Contact-mode scanning tunneling microscopy experimental technique employed for tunneling magnetoresistance measurements

V. Podgursky, R. Adam, M. Teske, M. Krämer, and R. Franchy

Citation: Review of Scientific Instruments 77, 033906 (2006);

View online: https://doi.org/10.1063/1.2185152

View Table of Contents: http://aip.scitation.org/toc/rsi/77/3

Published by the American Institute of Physics

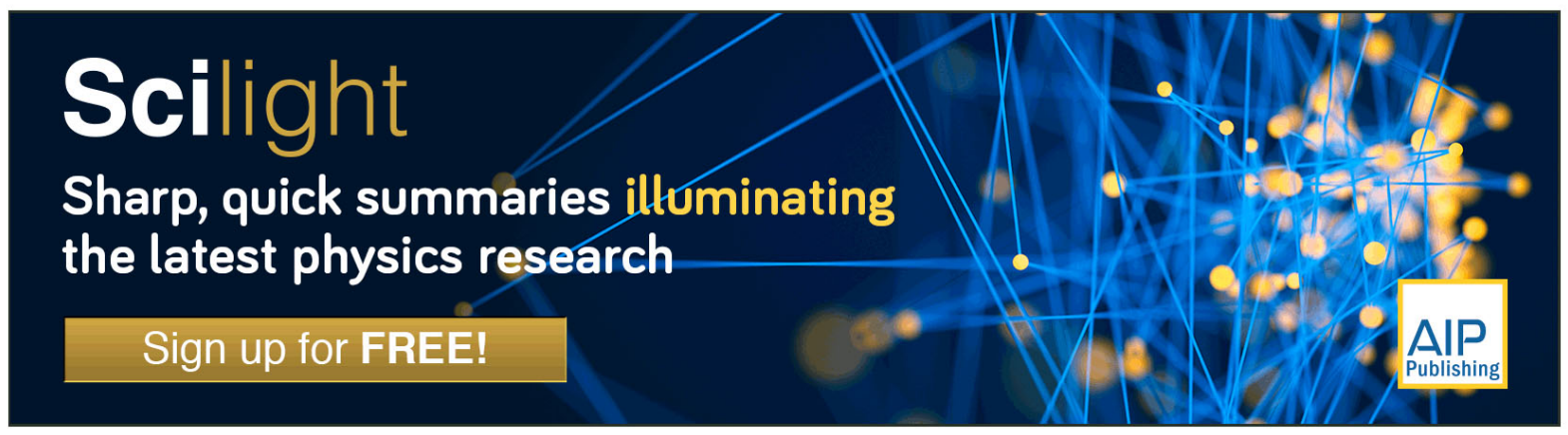




\title{
Contact-mode scanning tunneling microscopy experimental technique employed for tunneling magnetoresistance measurements
}

\author{
V. Podgursky ${ }^{\text {a) }}$ \\ Department of Materials Technology, Tallinn University of Technology, Ehitajate tee 5, 19086 Tallinn, Estonia \\ R. Adam, M. Teske, M. Krämer, and R. Franchy ${ }^{\text {b) }}$ \\ Institut für Schichten und Grenzfächen, ISG 3, Forschungszentrum Jülich GmbH, D-52425 Jülich, Germany
}

(Received 28 March 2005; accepted 8 February 2006; published online 24 March 2006)

\begin{abstract}
We employed contact-mode scanning tunneling microscopy technique to perform systematic measurements of micrometer-sized $\mathrm{Co} / \mathrm{Al}_{2} \mathrm{O}_{3} / \mathrm{Co}$ magnetic tunnel junctions (MTJs). Magnetic multilayer was grown by means of magnetron sputtering, followed by patterning of MTJ on top of FeMn antiferromagnetic bias layer into an array of rectangular mesa structures by standard photolithography. The maximum of $12.5 \%$ tunneling magnetoresistance at room temperature was measured for up to $40 \times 40 \mu \mathrm{m}^{2}$ test MTJs. () 2006 American Institute of Physics.
\end{abstract}

[DOI: $10.1063 / 1.2185152]$

\section{INTRODUCTION}

Tunneling magnetoresistance (TMR) effect continues to attract interest due to its potential importance for the information technology. The random access memory (RAM) based on the magnetic tunnel junctions (MTJs) has a potential to replace current complementary metal-oxide semiconductor (CMOS)-based memories. ${ }^{1,2}$ The nonvolatility is one of the major advantages of the magnetic RAM (MRAM) in comparison with the state-of-the-art memories. MTJ development focuses on the TMR value increase as well as on the improvement of MTJ parameters spread along the wafer. One of the crucial research task is a MTJ miniaturization to achieve minimum possible cell size and, consequently, to achieve maximum memory storage capacity. Currently, it is relatively easy to pattern arrays of multilayer magnetic structures in micrometer and nanometer ranges employing electron-beam lithography. Systematic investigation of submicrometer-sized multilayer structures, however, is not straightforward due to the device edge isolation and problems with upper electrode contacting. Recently, TMR response from samples down to $50 \times 50 \mathrm{~nm}^{2}$ was detected using atomic force microscope. ${ }^{3,4}$ In the present work, we demonstrate the scanning tunneling microscopy (STM) technique operating in both tunneling and contact modes employed for characterization of arrays of micrometer size MTJ in magnetic field up to $0.3 \mathrm{~T}$. This technique is, in principle, capable of device characterization in nanometer range.

\section{EXPERIMENT AND RESULTS}

In the present work, a $\mathrm{Ta}(5 \mathrm{~nm}) / \mathrm{NiFe}(3 \mathrm{~nm}) /$ $\mathrm{Cu}(20 \mathrm{~nm}) / \mathrm{NiFe}(3 \mathrm{~nm}) / \mathrm{FeMn}(20 \mathrm{~nm}) / \mathrm{Co}(3 \mathrm{~nm}) / \mathrm{Al}_{2} \mathrm{O}_{3}$ $(1.3 \mathrm{~nm}) / \mathrm{Co}(10 \mathrm{~nm}) / \mathrm{Au}(5 \mathrm{~nm})$ multilayer was grown on top of Si substrate covered with $1000 \mathrm{~nm}$ of $\mathrm{SiO}_{2}$ (Fig. 1).

\footnotetext{
a) Author to whom correspondence should be addressed; FAX: +372620 3196; electronic mail: vitali.podgurski@ttu.ee

${ }^{b)}$ Deceased.
}

Arrays of MTJ were defined by standard photolithography following by Ar ion-beam etching. The test arrays contained $40 \times 40 \mu \mathrm{m}^{2}$ in size MTJ devices. The resistance and TMR value were collected from measurements on 51 junctions. In the initial measurements, relatively large area of test devices was chosen for the sake of simpler fabrication and straightforward testing.

Figure 2 shows a setup schematics customized for MTJ measurements in contact-mode STM. All parts of STM were built from nonmagnetic materials. In order to prevent a saturation of preamplifier due to high current in contact mode, a new preamplifier was included into the setup, as shown in Fig. 2. A quality of Pt-Ir tip can be controlled in standard noncontact mode by a surface topography scanning. The noncontact mode can be switched to the contact mode by disconnecting a feedback loop; it prevents the tip withdrawal

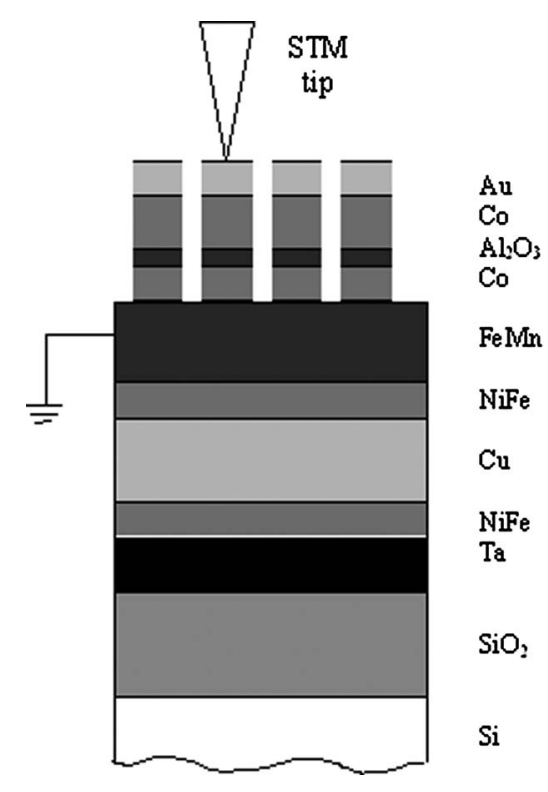

FIG. 1. Cross section of MT junction. 


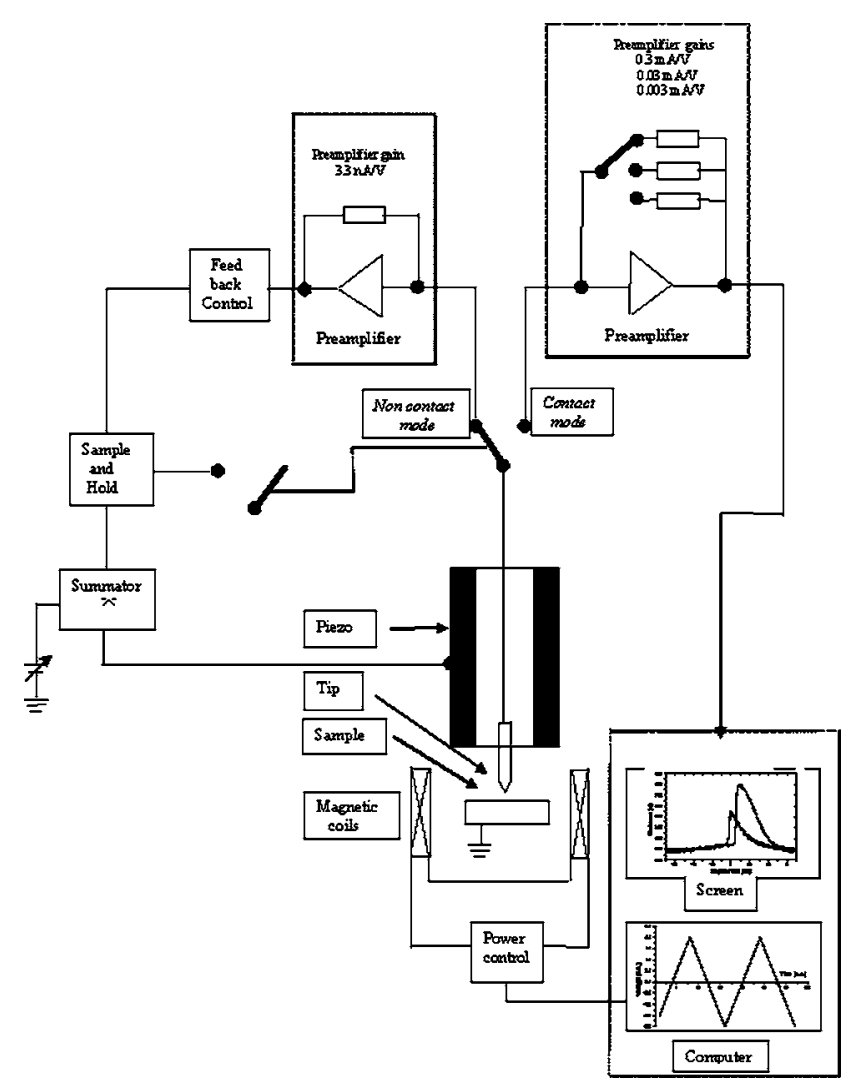

FIG. 2. Setup schematics of normal and contact-mode STM.

from the sample during measurement. Entire setup was placed in a magnetic coil capable of generating a static external magnetic field up to $0.3 \mathrm{~T}$ in plane of the surface of the sample and was controlled by a computer. All measurements were performed at room temperature in the air and the whole system was fixed on top of the vibration isolation table.

Figure 3 shows microscope image of the MTJ array containing $40 \times 40 \mu \mathrm{m}^{2}$ structures. The device separation was

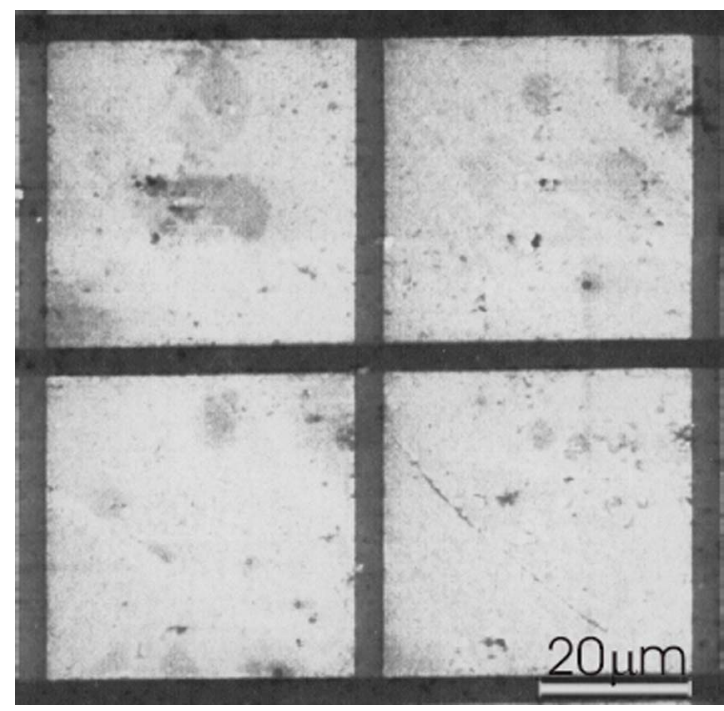

FIG. 3. Scanning electron microscopy image of $40 \times 40 \mu \mathrm{m}^{2}$ size junction.
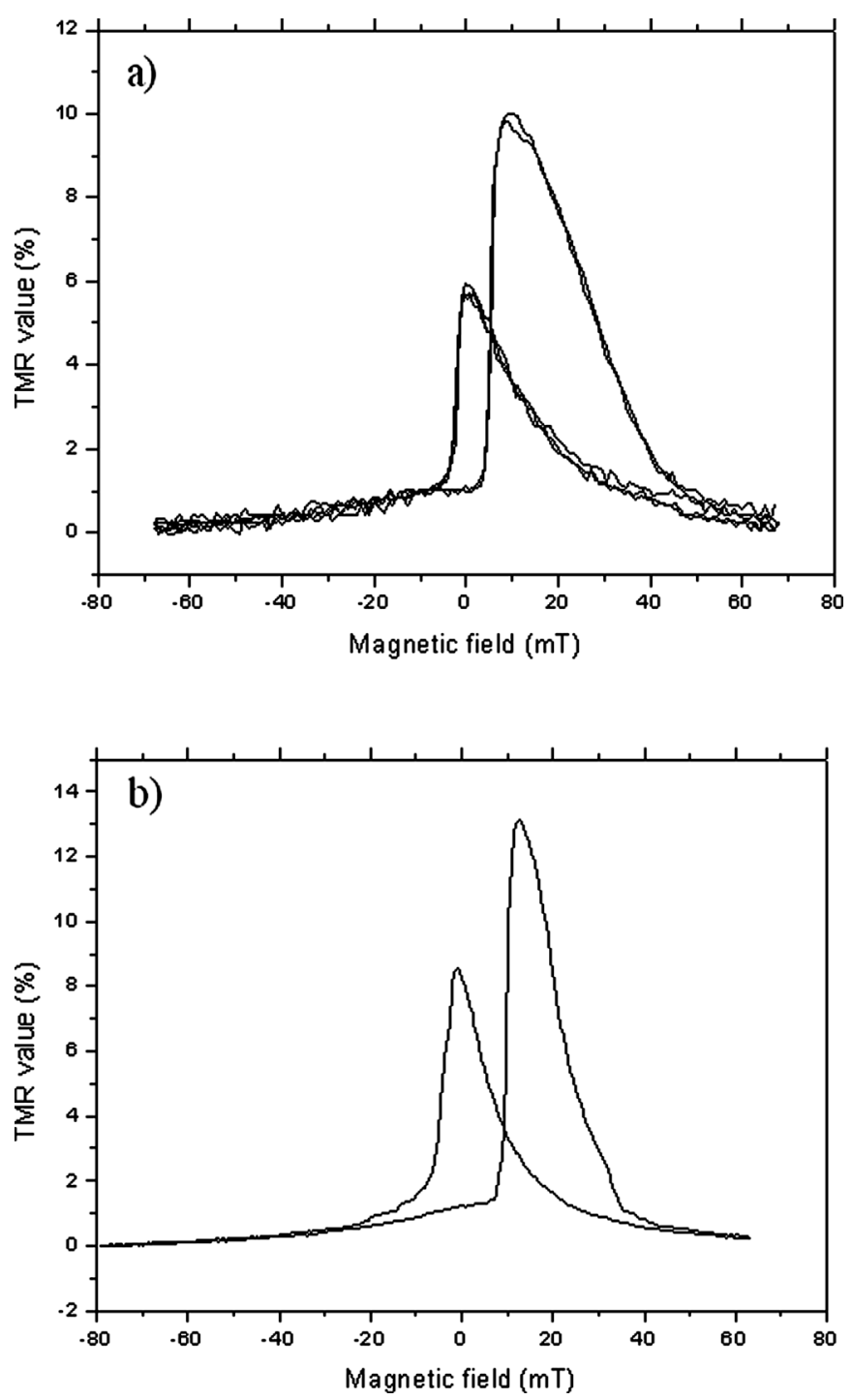

FIG. 4. (a) The magnetoresistance curve taken from $40 \times 40 \mu \mathrm{m}^{2}$ junction by means of contact-mode STM and (b) by standard four-point contact method.

$\sim 5 \mu \mathrm{m}$. Figure 4(a) shows a TMR curve of single 40 $\times 40 \mu \mathrm{m}^{2}$ junction measured by STM in contact mode. Because of the antiferromagnetic coupling between FeMn and $\mathrm{Co}$, the devices are exchange biased; hence a shift of the TMR curve along the magnetic field axis can be observed. A stability of the contact-mode STM measurement is good: The TMR curves practically do not differ after several sweeps of magnetic field, see Fig. 4(a). In addition, a shape of the curves resembles in details the one obtained from four-point contact measurements, see Fig. 4(b), and as well as found in Refs. 5 and 6. The MTJ dc bias voltage was $0.02 \mathrm{~V}$, which results in about $85 \mathrm{k} \Omega \mu \mathrm{m}^{2}$ of the MTJ resistance, see Fig. 5(a). The typical TMR value of the measured MTJs varies from $8 \%$ to $11 \%$ along the chips, with a maximum of the TMR value of $12.5 \%$, see Fig. 5(b). The values obtained by STM are in good agreement with the standard four-point contact measurements, namely, about 13\%, refer to Fig. 4(b). 


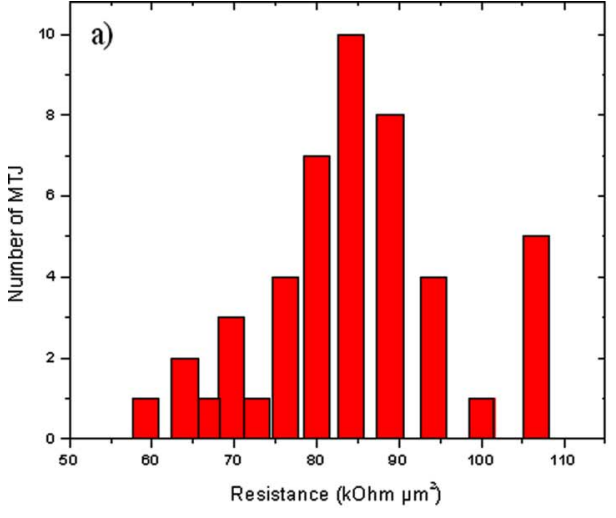

ACKNOWLEDGMENTS

The authors thank DI Werner Hürttlen for software development and technical assistance and Udo Linke for help with SEM measurements.

\section{${ }^{1}$ S. S. Parkin et al., J. Appl. Phys. 85, 5828 (1999).}

${ }^{2}$ Nanoelectronics and Information Technology, edited by R. Waser (Wiley-

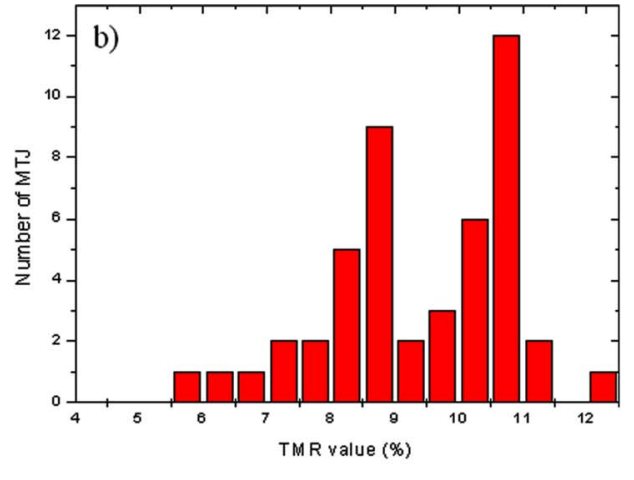

FIG. 5. (a) The distribution of resistance $\left(\mathrm{k} \Omega \mu \mathrm{m}^{2}\right)$ and (b) the distribution of TMR value collected on 51 junctions.

VCH, Weinheim, 2003).

${ }^{3}$ H. Kubota, Y. Ando, T. Miyazaki, G. Reiss, H. Brückl, J. Wecker, and G. Gieres, J. Appl. Phys. 94, 2028 (2003).

${ }^{4}$ H. Kubota, G. Reiss, H. Brückl, W. Schepper, J. Wecker, and G. Gieres, Jpn. J. Appl. Phys., Part 2 41, L180 (2002).

${ }^{5}$ B. Diouf, L. Gabillet, A. R. Fert, D. Hrabovsky, V. Prochazka, E. Snoeck, and J. F. Bobo, J. Magn. Magn. Mater. 265, 204 (2003).

${ }^{6} \mathrm{H}$. Wieldraaijer, J. T. Kohlhepp, P. LeClair, K. Ha, and W. J. M. de Jonge, Phys. Rev. B 67, 224430 (2003). 